\title{
Doing Inventing in the Library. Analyzing the Narrative Framing of Making in a Public Library Context
}

\author{
Gro Skåland *, Hans Christian Arnseth and Palmyre Pierroux \\ Institute of Educational Research, University of Oslo, 0317 Oslo, Norway; h.c.arnseth@iped.uio.no (H.C.A.); \\ palmyre.pierroux@iped.uio.no (P.P.) \\ * Correspondence: gro.skaland@iped.uio.no
}

Received: 5 May 2020; Accepted: 1 June 2020; Published: 10 June 2020

\begin{abstract}
In this article, we examine how creative making is framed in a public library setting. We pursue this topic by focusing on the trajectory of a group participating in "The Inventor Course" during a school trip to a library. Video recordings of the maker activity comprise the primary data for analysis, supplemented by ethnographic notes. Analysis of the group's interactions shows how different frames for inventing are acted out and intersect during the activity. We describe these frames as inventing as invention, inventing as exploration and inventing as narrative. Findings indicate that a narrative frame is a fruitful approach to making in a library setting and that narratives performed in dialogue with children help them to make sense of their explorations.
\end{abstract}

Keywords: libraries and other cultural institutions; makerspaces; education and pedagogy

\section{Introduction}

In the Norwegian welfare state, public libraries have been important institutions for providing free access to a variety of media for all citizens. In recent decades, libraries in Norway have followed international developments, with the introduction of new activities and architectural spaces to accommodate societal change and novel forms of digital media. The introduction of makerspaces in libraries is one such change in existing practices, with "making" written into policy aims and plans to reinvent the library and give it new purpose in the current mediascape [1]. The rationale for providing makerspaces in libraries is usually taken from either do-it-yourself ethics (DIY) or neoliberal ideologies of innovation and competition, or a combination of the two [1,2]. DIY ethics focus on the possibilities of the individual to participate in cultural change, with activities often focused on finding solutions to local problems [2]. Innovation rationales, on the other hand, are more concerned with libraries providing public access to facilities that people can use to educate themselves for future job markets [1]. Makerspaces in public libraries, in this sense, serve national strategies for innovation and competitiveness.

In this study, we examine a making activity in a public library in Oslo that had the aim of introducing children to a future role in society as "inventors". The makerspace was a relatively new practice in this library, as was the course, which invited school classes (grades 4-7) to visit and participate in an activity specifically designed to foster children's creativity and innovation skills. Within the context of public library policy, this inventor course may be seen as a tool for empowerment, that is, that children should be given opportunities to practice skills and tools they need to participate in society [3,4]. More concretely, the pedagogical design of the activity, as described below, asks children to identify a problem they can solve by making an invention using Little Bits and other materials.

We examine in detail how the idea of being an inventor is enacted in interactions between the children and between the children and the library educators. We are interested in how the activity is 
framed for the children in terms of what is expected of them, what they are supposed to do, and with what tools. Further, we explore how library educators support the children's creative making processes in a relatively new makerspace practice, particularly how they use narrative, or storytelling, as a resource to frame the activity in particular ways. To investigate this topic, we address the following research questions:

- How do children and library educators frame the concept of inventing in a makerspace activity?

- How and through what means do children create in collaborative making?

- In which ways do storytelling practices in libraries merge with practices of inventing in makerspaces, and what is the pedagogical value of this merging?

\section{Making in Public Libraries}

Public libraries have been highlighted as well-suited for makerspaces because the maker movement and the library share some of the same core values [2,5]. Libraries have a long history of providing public access to information, with access to tools for digital production included in a broad understanding of this democratic principle [1,6]. In a study of how librarians talked about access and freedom of expression in relation to their library's maker practice, Barniskis interviewed nine librarians responsible for makerspaces [3]. One finding was that the librarians viewed "access to tools of production and creative expression" an important instrument for reducing socioeconomic and digital divides. This understanding of the library mission has been referred to as a performative turn, encompassing activities related to culture production [1] and the fundamental idea of the maker movement as a revolutionary shift from consuming to making things [3].

An ethnographic study of public library makerspaces in the Nordic countries explored how such performative activities are connected to different rationales [1]. The study found that "making" was a category of its own, grounded in economic argumentation and focused on the library as producer of tomorrow's entrepreneurs. Rationales for including performing arts or DIY projects in the library, however, were not the same. Instead, access as democratization and empowerment was a rationale for art programs, which typically were designed to foster artistic expression and civic engagement by strengthening personal or group identity. The conclusion argues for a democratization and empowerment rationale for library makerspaces, leaving the innovation rationale to other actors. While this conclusion is rather typical for researchers in this field, it also underscores how creativity and invention become linked with ideals of democratization and empowerment [2].

In a discourse analysis of research articles and blogposts spanning from 2012 to 2014, Willet found mostly references to DIY ethics. The possibility to bypass governments, institutions and other gatekeepers in production is understood as one of the main rationales for having a makerspace. Making as DIY ethics concerns providing alternatives to mainstream modes of production, finding solutions to local problems and giving voice to those otherwise not heard. The pedagogical framing of making in the reviewed articles also typically contrasted makerspaces with learning in school. While formal learning in schools was often framed as a teacher controlled instructional pedagogy with little connection to the real world, library making was described as an opportunity to expand formal STEM education to include real-world problems [2]. As informal learning activities, then, making in libraries may be conceptualized as affinity spaces where people with shared interests meet [7], learning through participation [8] and from being situated in a shared practice. These perspectives also align with constructionist views on participants as self-directed learners, tinkering with technology while inventing and developing prototypes [2]. An important tenet of constructionism is this concept of tinkering, a bottom-up approach to learning where the goals for making emerge during play [9]. Learning in constructionism-inspired environments is thus described as a dialogue with artefacts [10]. Children's thinking is represented in material form and revising thoughts becomes a matter of changing the external artefact [11].

While the above-mentioned aspects of learning in makerspaces are assumed to be realized through open access to tools or courses [4], there are few studies of how policies of access may affect patrons' 
making activities. A study by Barniskis [3] found that the social function of makerspaces was more apparent than actual innovative or creative work, and that librarians had difficulties facilitating creativity and prototyping. In particular, the use of 3D printers was described as a non-creative tool, as most of the 3D printing used existing models downloaded from the internet. The study concluded that tool access alone did not ensure the use of library makerspaces for creative endeavors, pointing to the need for research on the role of the librarian as a learning facilitator [3] and on what actually happens in these spaces [2].

Distinctions between learning theory and practice were also apparent in the study by Willett [4], which first interviewed and then observed librarians from different libraries participating in the same maker project. In the interviews, their references to the project emphasized terms such as "learning by doing", "exploratory", "experiential", "playful" and "hands on", suggesting constructionist perspectives on learning [4]. Observations of the science education project for children on circuitry, however, showed the librarians used of a combination of formal styles of teaching, such as showing the basic, and self-driven explorations. Willet concluded that there is a mismatch between what librarians think they do, and the actual pedagogy practiced. This finding is in keeping with previous research on informal makerspaces, which shows widely diverse practices [11]. Building on these findings, this study focuses on what children, teachers and librarians do in a making activity, considering the particularities of the public library setting.

\section{Analytic Concepts}

\subsection{Imagination, Creativity and Inventing}

Sociocultural approaches entail the study of how ideal and material tools mediate human activity [12]; in this case, how library educators and children use semiotic means to imagine, create and make meaning of their actions and what they produce "as inventing". For the purposes of this study, creativity is defined as "whenever a person imagines, combines, alters, and creates something new" ([13], p. 10). Further, imagination is understood as a dynamic and mediated process [14] that may be "triggered" by curiosity, interest and the sociomaterial features of a particular setting [15-17]. A generally accepted definition of interest is a liking, preference, or engagement with content in a context, at a specific point in time, both individually and in groups $[17,18]$. Examples of sociomaterial features that may trigger interest include objects, texts, interactions, talk or even sounds. Any kind of recorded or synthesized sound, for example, may trigger an imagination space to explore symbolic or conceptual relationships [19]. To explain how different kinds of resources become blended with concepts, such as "inventing", Hutchins [20] proposed the notion of "imaginary material anchors", whereby the imagination is mediated by cultural forms (e.g., materials, gestures and social interactions) during ongoing activity [20]. We draw on these concepts to analyze how features of the library makerspace mediate the children's imagining processes and their creative collaborative work as "inventors".

\subsection{Framing}

Organized as a school field trip to a library makerspace, both formal and informal learning practices intersect in the inventor course [21]. Accordingly, different institutional practices-in schools and in public libraries-play a role in how the participants frame the activity; that is, how the activity makes sense for the participants and the consequences this has for their participation. For Goffman, "frames" is a concept for understanding how activities and actions are organized and possibly structure people's interpretations and perceptions of them [22]. Framing describes a process that helps people understand what is going on in a situation by organizing experiences into meaningful units, which, in this case, are defined by the library as part of an inventing activity.

In informal learning research, framing has been a useful concept for studying children and young people's meaning making in exhibitions, workshops, and creative activities in science, history and art museums $[23,24]$. In these settings, children may break frames that educators introduce; for example, 
when determining whether to approach an activity as "educational" or not, or whether an object is an "invention" or not. As in the inventor course, which straddles formal and informal learning contexts, a lamination of frames may exist simultaneously [22]. Lamination refers to how different frames overlap and intersect in interaction. In such situations, one participant may take on a "definer" role, rendering one action "out of frame" and another a "proper frame". An outermost frame determines the status of frames. In this case, the outermost frame tells the participants that what is happening is inventing, during a school visit to the library. Violations of expected behavior in a situation may be rejected as inappropriate, or be perceived as confusing, and participants may become uncertain as to the applicable rules. In the context of "making," organized as a school trip to the library, expectations may be unclear for the students, and we use the concept of framing to analyze the frames participants perform in their efforts to figure out what the rules are. Importantly, negotiations of what constitutes a relevant frame are not necessarily performed verbally; framing may be negotiated tacitly, through ways of doing things and the habitual practices each participant brings to the situation [22]. Frames are also rhetorical tools in negotiations, where verbal and embodied means represent different opportunities for persuasion [25]. This study draws on the concept of framing to explore how established practices by librarians in this branch of the library-habituated frames-are made relevant during the inventor course activities, as well as how students frame their own activities. Storytelling, for example, is a frame that was noted during ethnographic observations of the librarians' educational practices, apart from the inventor course. In the analytical approach, we were thus sensitive to the use of narrative as a way of framing the activity. We analyze how participants use narratives to construe frames that function as resources for meaning making. Bruner suggests that the interpretative quality of narrative meaning making allows for negotiating our understanding of the world [26]. Together, these concepts constitute the analytical framework for our investigation of how participants "do inventing" in a library makerspace.

\section{Data Collection, Methods and Analytic Approach}

The research design was focused on collecting data for the analysis of participants' verbal, embodied and collaborative interactions during a two-hour making activity, an "inventor" course in a public library in Oslo, Norway $[27,28]$. To capture participants' interactions, video recordings, supplemented by ethnographic notes [29], were made of five school classes from four different schools that had registered for the course. Ethnographic notes from approximately $34 \mathrm{~h}$ of participant observation inform the study, but the video recordings serve as primary data for this analysis. The participants were between ten and twelve years old, the library's recommended age group. The selection of groups for filming was made by the respective class teachers, based on the students' submission of formal parental consent forms that had been supplied by the researchers prior to the visit. In sum, ten groups of three to four children were filmed over a period of several months in 2018 and 2019 , about $20 \mathrm{~h}$ of video recordings.

The analysis first sorted video recordings from all groups according to the structure and sequence of the course acitivites, accompanied by detailed notes on interactions within each group during each sequence. Through this process of structuring the data, patterns, regularities and "breaks" in interactions within and across groups became visible [30]. Patterns in the collaborative flow of student groups, in their use of materials, and in types of teacher facilitation, are examples of distinguishable features from each phase of the activity. For this study, which has a research focus on how the task of being an inventor was communicated, facilitated and enacted using the resources in this particular makerspace context, it was decided to follow the trajectory of a group of three ten-year-old boys as a case study [30]. The selection of the group was also informed by a research interest in the educational role of the librarians and their professional knowledge practices.

These children attended the course with their class, their teacher and two teacher assistants. Two librarians were present, one with main responsibility for the activity and the other in an assistant role. Librarians in this library alternated in teaching the course. On this day, the participating librarians 
were from the children's literature department, defined as the "storyteller's division" in policy and practice. The two librarians most frequently teaching the inventor course had a background as professional storytellers, although the librarian in charge on this day did not.

Recordings of the group's interactions during instruction, inventing, and presentation activities were transcribed in full length, attending to the boys' talk, bodily orientations, gestures and use of materials. Concepts were tentatively introduced after the first round of data selection, including the general idea of framing as an analytical perspective [22]. Four extracts were then selected as episodes for detailed analysis. The interaction analysis method, as well as procedures for selecting and transcribing extracts and episodes, are adopted from approaches established by Jordan and Henderson, and Goodwin [28,31].

\section{Analysis}

\subsection{Description of the Activity}

This city library provides a makerspace for their visitors, with one open makerspace for youth and adults and an annual inventor course offered for primary school children. The course lasts for approximately two hours, with an inventing part that lasts about $40 \mathrm{~min}$. The course has a fixed design, organized in five consecutive parts. First, there is orchestrated dialogue on the topic of inventions. This session can be described as a teacher-led, whole-class question and answer dialogue. Kira (pseudonym), the librarian in charge of the course, introduced the course with a question directed to the children, "what does invention mean?" Following suggestions by the children, Kira read a definition of invention from a Norwegian encyclopedia that was also shown on a slide presentation at the front of the room (Figure 1). The following definition was given: "Invention. A Practical solution of a technical problem using natural materials and or energy. The invention may be a product or process." The children were asked to suggest inventions they know about, and a standard question followed every suggestion: "what kind of problem do you think this invention has solved?" This was repeated throughout the dialogue session; every invention has a connected problem. Usually, the librarians have prepared a story about a Norwegian invention and on this day, Kira told the children about a brewer who had a problem of having enough bottles and invented the principle of bottle return. Second, an informative introduction to how Little Bits works is shown on the screen, along with examples. Kira pointed to different colors and explained their different functions. The section concludes with a video provided by the Little Bits company, showing three products made with Little Bits: a spin roller, a drawing machine and a walking paper figurine. Third, an instruction session guides the children in how to make an electrical circuit from a selection of Little Bits. The session was led by Kira, and the children were expected to try one piece at a time in concert with her. The bits introduced in the whole-class instruction are a battery, a lightbulb, a temperature sensor, a fan, an on/off switch, wheels and a motor-driven wheel axle. Fourth, the main inventing task takes place and the children are expected to invent something using Little Bits. The task is formulated on the screen: "Make your own invention in groups. The invention should solve a problem. The invention should have a name." The resources provided for each group are a large box of Little Bits and arts and crafts materials: paper cups and plates, feathers, tape, scissors and tissue paper. The crafts materials are handed out at the start of inventor section. Both teachers and librarians facilitate the children's work during the inventing task, but the group in this case is left alone for long periods. Finally, the fifth part is group presentations in front of the class, with the librarian orchestrating the session. The episodes below are extracted from transcripts of the last three parts: instruction, inventing task and group presentation. 


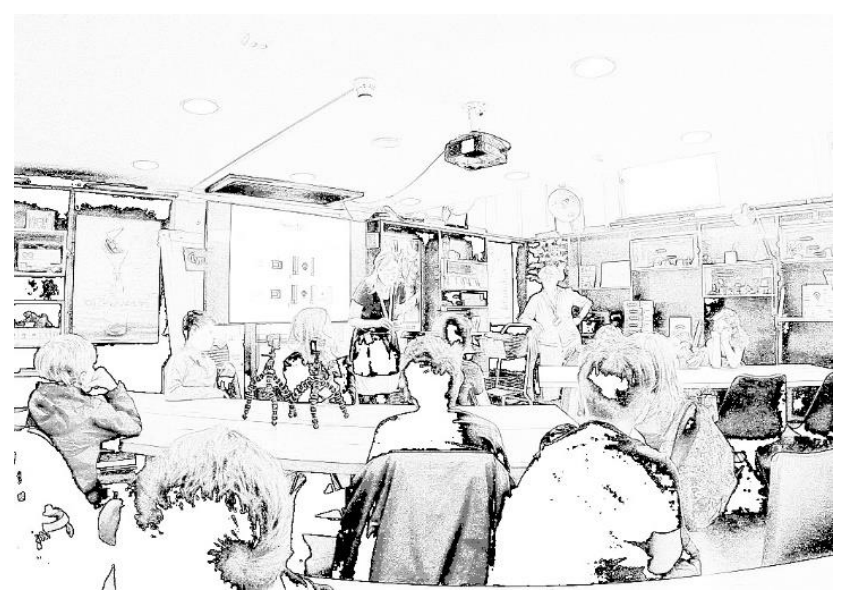

Figure 1. Makerspace setting for inventor course, with librarian standing.

\subsection{Episode 1. Instruction Session: Playing 'off Task'}

The children were told to find a light bulb from the Little Bits box and follow the librarian's instructions on the screen at the front of the room. Abdi had just picked up a battery and Rufus and Abdi quickly mount the light bulb to the battery. Then Abdi picks up a piece from the box that is not included in the task instruction and Rufus asks him to stop, insisting on following the rules and working on the official task. Abdi listens to him and puts the piece back in the box. Rufus picks up the piece discarded by Abdi only a few seconds earlier and from this point on their activity changes (Table 1). They follow the librarian's instructions while also exploring the pieces in the box.

Table 1. Excerpt of dialogue: Playing off task.

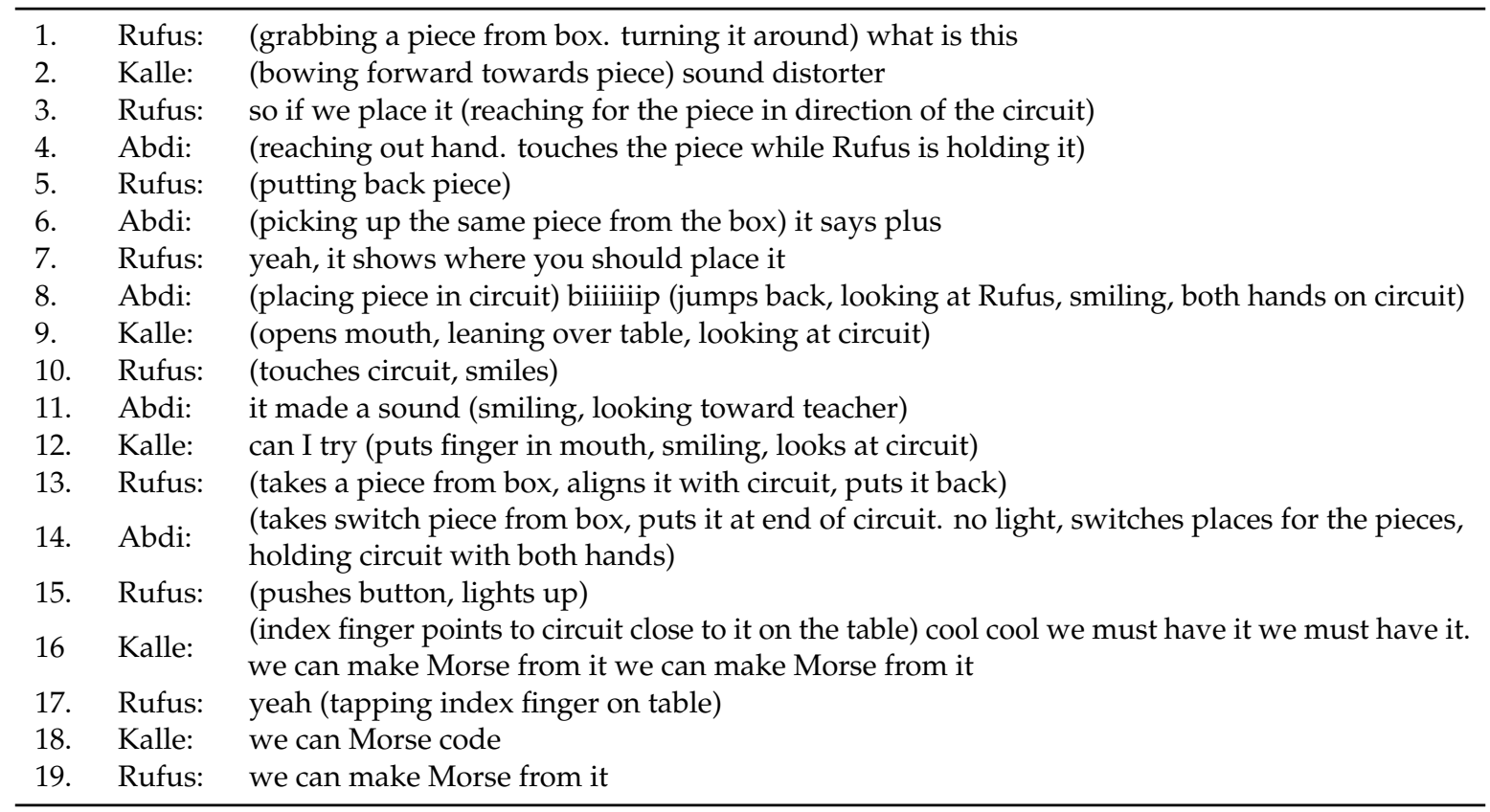

Rufus finds a random bit and asks, "what is this?" (1). Kalle, who had attended a similar course with his friend and mother, knows the function of the bit and says the piece is a sound distorter (2). Rufus places the bit back into the box (3), but Abdi picks it up again (6) saying the bit has a plus sign on it. Rufus concludes the plus sign is showing where to place the bit (7). Abdi places the bit into the circuit, and the sound distorter reacts immediately. The sound makes him jump in his chair, and he smiles in the direction of Rufus (8). Kalle's reaction is to lean his torso closer to the circuit, and his 
mouth is wide open (9). Rufus reacts by touching the circuit and smiles (10). "It made a sound", Abdi says, and he looks in the direction of one of the teachers (11). Then Kalle asks to try the circuit (12), but none of the boys respond to his request. Abdi continues to explore the bits. He takes a switch piece from the box and mounts it to the end of the circuit. Nothing happens this time. Then he switches the places of two of the bits in the circuit (14). Now, when Rufus pushes the button, the bulb emits a rhythmic flashing (15). Kalle raises his voice the moment the button shows the potential of turning the light on and off, repeating each utterance: "cool cool, we have to use this, we have to use this. We can make a Morse code out of it, we can make a Morse code out of it" (16). Rufus confirms the idea with a "yes" and a rhythmic tapping on the table with his index finger (17). Kalle elaborates that they could make codes with the Morse code (18), and Rufus acknowledges that, repeating that they can make a Morse code (19).

\section{Laminating Frames}

There is a conflict in the beginning of this excerpt in terms of how two of the boys frame the activity. The task instructs them to follow a procedure but Abdi chooses to explore, picking up a piece in the box. Rufus disagrees with Abdi's frame breaking at first, but then follows Abdi's example only seconds later. In the ensuing collaboration, we witness how a lamination of frames is performed [22]. Abdi and Rufus continue to explore the Little Bits as a sidetrack to ongoing instruction, challenging the frame established by the course pedagogy. Instead, the activity has an inventing as exploration frame. To start tinkering and exploring with the bits and pieces is unproblematic for the children. We might also argue that it is not particularly surprising that they want to explore things that are laid out before them immediately, rather than waiting for the educator to tell them when to do what. They take out the pieces as instructed, but also many more, and they put them together in different ways to see how the pieces work at a tempo much faster than the instruction. Their dialogue is often non-verbal; for example, when Rufus touches the button and the light turns on and off. The touching of pieces defines what their dialogue is about, that is, their touching has a rhetorical function during their exploring activity [20,25].

Sound becomes a material anchor for Kalle's imagination when he suggests that the button functions as a Morse code, and a third frame for the activity is introduced. There are two interesting aspects of this event. First, it shows that their activity is about following instructions, exploring Little Bits, and about making an invention-an inventing as invention frame. The exploring frame established in the group is now oriented toward searching for ideas for what the pieces might be, as if they were making a real invention. This is a role Kalle assumes during the entire session, and the excerpt above is a typical example of this frame. His suggestions for what the Little Bits might be align with the whole class dialogue about invention, where the focus is on invention as a product and the stories connected to these products.

Zooming in, a second interesting aspect of this excerpt is the process by which a new idea emerged. Through play with the multimodal Little Bits pieces, the sound and light triggered an imagination space [19]. The sudden squeaky sound and rhythmic flashes of light appeared when Rufus turned the switch on and off and these modalities triggered Kalle's associations with Morse code; the pieces assumed new semantic and referential properties and the materials were re-contextualized from Little Bits pieces to a Morse code signal system. Moreover, this imagination space could be further developed and shared by all the participants. Although their talk may not indicate that Rufus, Abdi and Kalle are collaborating while exploring, they nonetheless occupy this shared imagination space. Their engagement is signaled through signs of emotions, such as gazing and smiling towards the teacher; shows of surprise, such as open mouths and repeating each other's utterances in verbal and gestural modes (tapping finger on table in a Morse-code rhythm); and shouts of joy when accidentally discovering that they could make Morse code, underscoring the important role of interest and emotion in triggering imagination and creative processes $[17,18]$. 


\subsection{Episode 2. Inventing Task: What Counts as an Invention}

The next two excerpts take place during the inventing task. Earlier, when Kira led a whole-class discussion on what constitutes an invention, two points were emphasized: an invention is something new and an invention solves a practical problem. Kira explained this using a narrative about a car: "Why do we need a car? Because we need to move heavy things from one side to the other-from IKEA to the house. Suddenly you have a car, and the problem is solved." The excerpt below starts as the boys are discussing what qualities an invention should have (Table 2).

Table 2. Excerpt of dialogue: What Counts as an Invention.

\begin{tabular}{|c|c|c|}
\hline 1. & Kalle: & we can't make sound because that is already invented (flat hand in front of Rufus) \\
\hline 2. & Rufus: & no but we can try to make a: a new type $\uparrow$ of Morse code (gazing up and away from Kalle) \\
\hline 3. & Kira: & then let's say you have forty minutes to work \\
\hline 4. & Kalle: & hhh so little time (turning head rapidly towards Rufus) \\
\hline 5. & Rufus: & $\begin{array}{l}\text { ka-(taking a piece from the box) I want to make something first (takes cord with battery } \\
\text { from Abdi's hand as they are holding the fan together. attaches a piece to the cord, takes it } \\
\text { off again) then we need this (takes another piece from the box and attaches it to the end of } \\
\text { the fan) like that } \uparrow \text { (attaching a piece) like that }\end{array}$ \\
\hline 6. & Kalle: & why can't we make something that serves (hands folded at the table) \\
\hline 7. & Rufus: & $\begin{array}{l}\text { biip biip bipbiiiip (pushes the button on the buzzer piece he attached to the end of the fan, } \\
\text { leans back smiling and places his hands on the table. Abdi is holding at the other end) }\end{array}$ \\
\hline
\end{tabular}

Kalle starts out by stating that they must invent something other than sound because sound is already invented (1). Rufus argues that while they cannot invent sound, they can try making a new type of Morse code (2). At this point, Kira informs the whole class about the limit of forty minutes for the inventor task, and Kalle reacts with rapid breathing to show that this is too little time (4). In the next line (5), Rufus takes a piece from the Little Bits box. He says he wants to make something first, taking the battery from Abdi's hand. Abdi continues to hold the circuit together with Rufus while Rufus tries to attach one piece after the other (Figure 2). Kalle watches while keeping his hands on the table, suggesting making something that "serves" (6). Rufus responds by pushing the button on the pieces he just assembled, demonstrating the beep with a smile (7).

Negotiating Inventing as Invention

Episode 2 shows how Rufus and Kalle have different ideas about what it means to invent something. Kalle states that an invention must be something completely new, something that does not exist here and now. Rufus, on the other hand, argues that working further on something that already exists, like the Morse code, counts as an invention if they find a new tweak on it. Understanding an invention as something never seen before seems to hinder Kalle's imagination process, as does the challenge of working with Little Bits as an imaginary material anchor [20]. In other words, it seems difficult for Kalle to reconcile the idea of a new invention with the material imagination space in which they are working [19]. Following the inventing as invention frame, he then suggests making something that "serves", expanding the imagination space with a new idea. This idea is connected to the cups and plates and other materials on the table and is thus triggered by materials in the same way as the Morse code invention. However, his idea and argument about the need for something new is ignored by Abdi and Rufus. One reason may be that the two boys are engaged in different modes of communication during this interaction [25]. Kalle uses a verbal mode to argue his understanding of an invention as something "new", and this seems to keep him from participating in the inventing process going on. His suggestion is disconnected from the mode of practical experimentation with physical objects that Rufus and Abdi are engaged in, the activity of making, and he is thus outside the material imagination space they share [19]. Further, his verbal approach has consequences for the impact of his rhetorical argument [25], as the materials Kalle refers to are not yet activated within this space. 


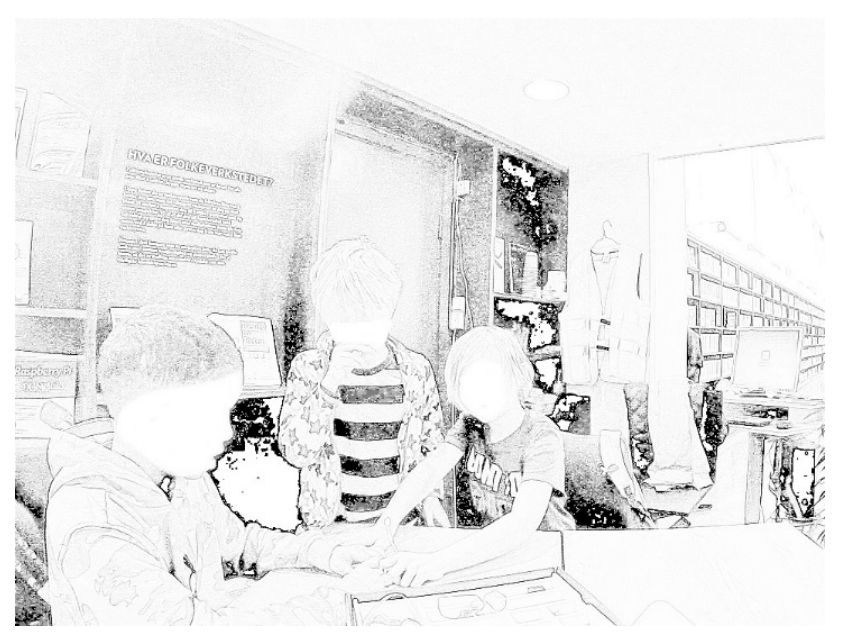

Figure 2. Group of boys collaborating on inventing.

\subsection{Episode 3. Inventing Task: Identifying a Problem}

The inventing task asks the children to define a real-world problem to solve with an invention made of Little Bits and crafts materials. However, finding a problem that their invention can solve is a difficult task for the children to solve on their own. In many ways this activity is similar to doing school, where the focus is on making something that can be assessed. This contrasts with the maker ethos which is more focused on creative exploration. Having said that, as we demonstrated above, the institutional framing does not determine what the children do and how. During iterations of their invention, the Morse code idea has grown into a platform containing several elements. These include a paper cup with a fan at the bottom that provides an air substitute in case of poisonous air; a temperature sensor and a lightbulb with no explanation of their function; and the Morse code signaler. The boys are tapping into ideas for possible problems their invention could solve, but why and when one might need a Morse code signaler or an alternative air supply has not yet been discussed. In this excerpt, Merete (class teacher) has just arrived at the table to talk to the group (Table 3).

Table 3. Excerpt of dialogue: Identifying a Problem.

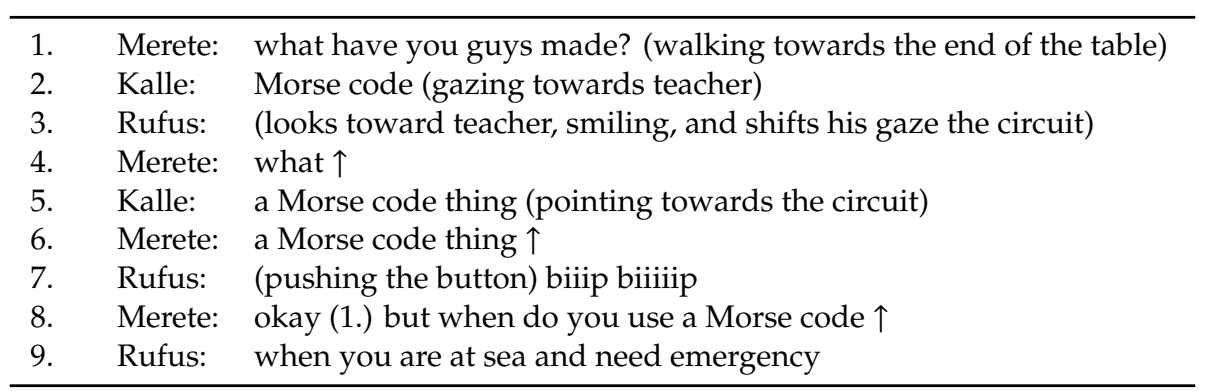

In this excerpt, the teacher asks the boys what they have made (1) and Kalle responds that they have made a Morse code (2). Rufus smiles and looks at Merete and then shifts his gaze toward the circuit (3). Merete does not recognize what is said (4) and Kalle nearly repeats his first answer, but now says "a Morse-code-thing" (5). Merete repeats this with a high intonation in her voice (6), while Rufus is pushing the button (7). Then Merete asks them when one might need a Morse-code-thing (8), and Rufus answers, "when you are at sea and need emergency".

Problem Solving Backwards: Narrating Inventions

The excerpt shows an attempt by the teacher to introduce a narrative frame that can facilitate the group's thinking about how what they have made is related to a problem that needs solving. The boys 
do not participate in adult "real world" practices, and do not have such problems to solve. What they have are many possible solutions from which a problem must be derived. The teacher helps the boys tap into possible real-world problems by introducing a narrative frame, shifting from problem solving to storytelling. She asks them to imagine when Morse code might be used. This question invites answers about the objectives of a potential user of Morse code, a possible cause for the need of such a tool, and what obstacles the user may be facing. Rufus answers that the place might be the sea and the need is unspecified emergency. This episode describes the invention through dramatization, in the same way as the librarian when telling the story of the brewer in the introduction. However, the teacher does not elaborate further on their narrative. Except for a name, the story contains what is required from the task: a problem and an invention that solves the problem.

As the time for group presentations approaches, Kira reminds the children to find a name for their inventions. She underscores that there is no need to stress about finishing-it is the idea that counts. The boys have called the invention different names during this last period of making: Emergency Situation, Emergency Situations, Save, The Emergency Situation, Emergency Sit, Emergency Sit Where You Are, Rescue Spaceship, Wall Machine, Rescue Rescue, and Problem Problem. When the time runs out, the three boys are first to present.

\subsection{Episode 4. Presentation: Kira Gives The Rescuer a Dramatic Role}

The last part of the program for the inventor course has the groups present their inventions to the class (Table 4). The three boys stand at the end of the table: Rufus in the middle, Abdi to his left and Kalle behind the two. The rest of the class serve as an audience from their respective places in the room. Kira oversees the presentation session and starts the conversation. The teacher, Merete, also comments during the session.

Table 4. Excerpt of dialogue: Kira Gives the Rescuer a Dramatic Role.

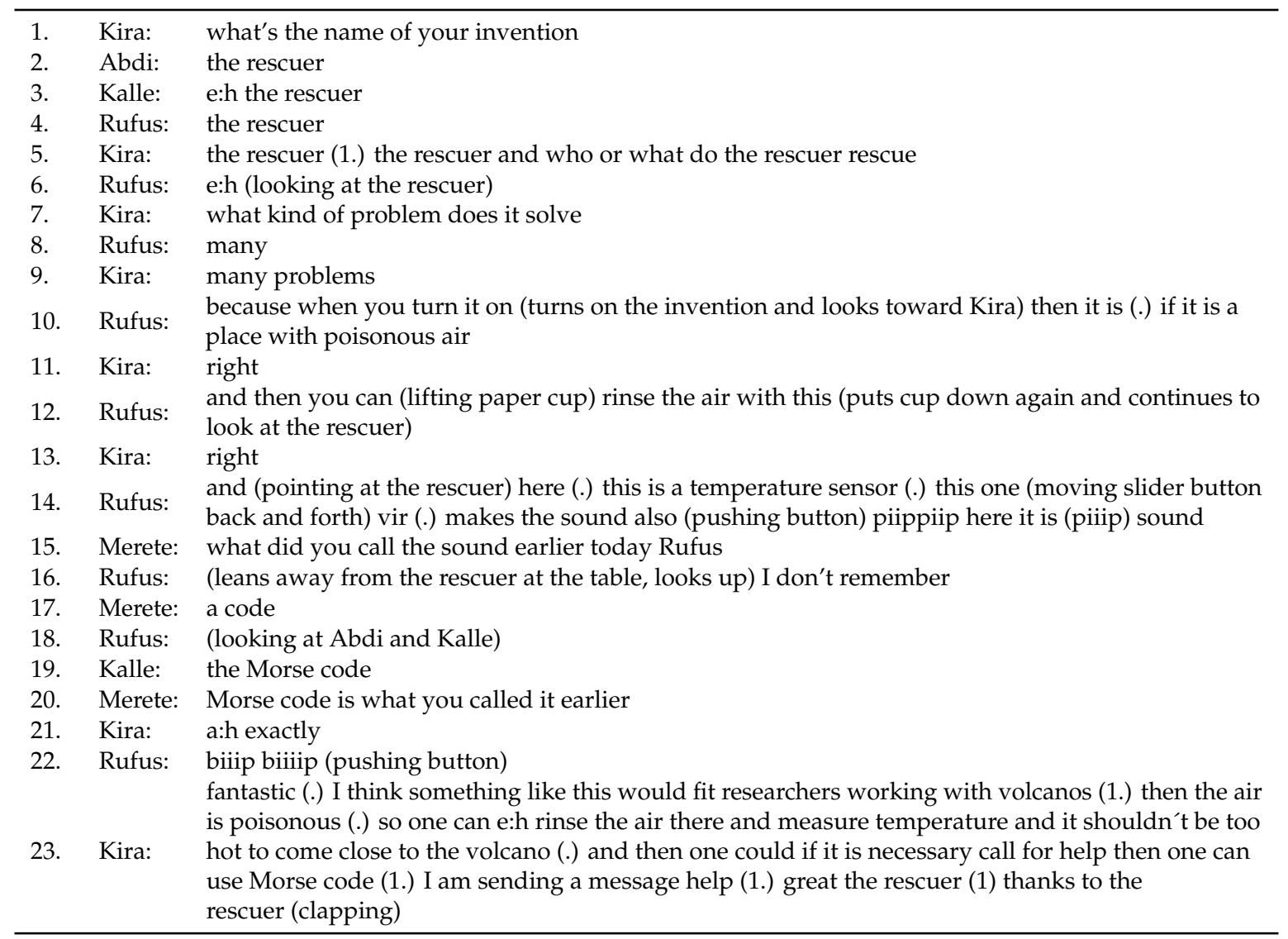


This episode shows the librarian opening the presentation by asking for the name of the invention, and the three boys answer, "The Rescuer" (1-4). Kira confirms the name twice and continues by asking who or what the rescuer is rescuing (5). Rufus is silent, looking at The Rescuer, and Kira reformulates by asking what kind of problem the rescuer solves (6-7). Rufus answers that The Rescuer solves many problems and Kira repeats this (8-9). Rufus explains that when turned on, The Rescuer will rinse poisonous air, lifting the fan-cup and turning on the machine (10-12). Kira confirms his explanation, and Rufus continues to explain that The Rescuer also includes a temperature sensor and a sound, demonstrating this by touching the sensor and sliding the button to make the machine beep (13-14). The teacher intervenes, asking for the name of the sound and reminding Rufus that he had referred to it earlier (15). However, when Rufus says that he cannot remember (16), the teacher prompts him by saying it was something with the word code (17). Rufus turns around to look at Abdi and Kalle, and Kalle says Morse code (18-19). Merete confirms, saying that Morse code was what Rufus had mentioned (20). Kira says "a: $h$ ", confirming that she understands the idea of the Morse code (21). Rufus replies by pushing the button (22). Kira uses the word "fantastic" about the invention, and then she suggests an alternative use of The Rescuer: it can be used by volcano researchers who need tools to measure temperature, rinse the air from poison and signal in Morse code in case of emergency (23).

\section{Implicit Expectations of Storytelling}

This episode shows how the task is linked with implicit expectations connected to the practice of telling stories, and how a narrative frame invites a certain casting, or emplotment, for stories about inventions [22]. Kira opens the presentation by following the expectations stated in the task, asking for the name of the invention. When the boys answer "The Rescuer", Kira asks questions about who or what The Rescuer is rescuing. Who are the characters in the story about The Rescuer and what is happening; what is the plot? None of the boys respond to this question, but Rufus explains that the problem is poisonous air and that the invention will clean the air if you are in a place where the air is poisoned. This is a problem the boys came up with during their making activity, after having mounted a fan in the bottom of a cup. As such, the problem of poisonous air and their solution addresses the task presented to the children; they have a problem, an invention to solve the problem, and a name for the invention. However, this episode shows that what is implicitly expected from the children is a story about the problem and how it was solved, in a manner not unlike everyday practices of telling stories [22].

During their presentation, Kira asks questions that guide them toward a coherent story about The Rescuer. When Rufus says that The Rescuer will clean the air if you are in a place where the air is poisoned, the story is still incomplete, not least because The Rescuer has many functions and only one has been explained. The character using the fan-cup is "you", having experienced the poisoned air, but it could also be me or someone else. The place is loosely defined as "a place" where the air is poisoned, and a cause is missing. However, a plot is emerging. We have a consequence, poisoned air, but its cause is unclear. Kira elaborates on the consequence in the plot by introducing volcanoes as a cause for the poisonous air, and she also suggests characters. The Rescuer is imagined to be used by volcano researchers and in the plot they experience poisonous air and extreme heat that will potentially lead to a crisis. The researchers need the tool invented by the boys; the temperature sensor helps the researchers avoid the heat and the fan helps rinse the air. In case of a breakdown, the Morse code device will be of good use. In this episode, The Rescuer has been given a central role in a drama featuring researchers as the main characters. The story establishes a place, characters and a dramatic plot. In this narrative, the characters are adults with high expertise within a profession.

\section{Discussion}

The research questions for this study ask how children and educators frame the practice of "making" in libraries, and in which ways the library setting may distinguish this makerspace context. We also wanted to understand the resources children draw on to creatively collaborate in an inventor 
course offered by the library. We explored these questions from a sociocultural lens, using Goffman's concept of framing [22]. By focusing on the trajectory of one group of children during the inventor course, we identified frames that the children and the library educators used to make sense of the overall frame of inventing. In the introductory part of the course, the children were not presented with a model of how inventors actually work. Rather, the library educator talked about inventing in terms of an invention, a finished product. We term this frame inventing as invention, a narrative about what has been made and not the process of making. The frame inventing as invention suggests that a process of design follows a linear structure, starting with ideas and ending in a re-presented material form [32]. This frame is typical of schooling where students are required to present a product for evaluation. We found that when following instructions, the boys in the group initially struggled to align their approaches with creative collaboration. This changed through a playful, exploratory approach to the materials, which we called an inventing as exploration frame. This frame is similar to the tinkering concept [11], but emphasizes the social, multisensory and affective aspects of exploring materials $[17,18]$. Moreover, we found that the multimodal properties of Little Bits triggered the children's interest and imagination, fostering the creative process. The inventing as exploration frame was driven toward ideas because of surprising sensory triggers evoked through play with the materials, which served as anchors for their imagination $[17,18,20]$. On a more aggregated level, we find the overall frame of inventing in this activity unclear [22], which may be one reason "doing inventing" was framed in such diverse ways. Furthermore, when children are trying to decode expectations of behavior in institutional practices of making, a dominant frame may be given more rhetorical power [25].

However, looking at the pedagogical value of different frames, we also identified the library educator's use of a narrative frame and its significance as a resource for the children in the making activity, using storytelling as a didactic approach to help them make sense of their inventions. Storytelling is part of everyday practice in the library and an established way of engaging in dialogue with children. According to Bruner, narratives are fundamental to human learning and have great pedagogical potential as a meaning-making tool [26]. There was an implicit expectation that the children in the course would present their inventions in the form of a coherent narrative, emphasizing the rhetorical power of storytelling as a skill to be mastered and perhaps more important than the actual making process and product [25]. In this case, the library educator's story about the group's invention illustrated for the children how narrative could be used to make sense of inventing activities as connected to solutions for real world problems. However, this pedagogical approach to storytelling also reflects the librarian's power to shape the narrative of the children's work from an adult perspective. Purposefully eliciting narratives from children that are related to problems closer to their worlds would likely resonate more powerfully, fostering a sense of ownership and identities among children as problem solvers. In this sense, although situated at a micro level of interaction, this study also looks upstream to connect to DIY rationales for library makerspaces based on notions of empowerment [3] and participation in cultural change.

\section{Conclusions}

We identified three different frames in the inventor course: the invention frame, exploration frame and narrative frame. These frames may appear in different constellations and have different outcomes for children. Whether they are seen as productive or not must be assessed in relation to what the participants want to achieve-including the institutional goals structuring the activity. Even though the course was situated in a library setting, it had school-like features. There might be several reasons for this, one being that the educational programs need to be seen as relevant to schools, and, by the same token, that the library needs to pay careful attention to curricular goals and objectives. Having said that, an interesting feature of the activity we observed concerns how library educators are able to draw on their storytelling expertise to support the children's meaning making.

To conclude, we propose the fruitfulness of using frames as a theoretical lens for studying making in institutional settings such as the library. This approach enables examining in detail how participants 
understand what is going on, which frames become dominant resources for sense-making, and how opportunities appear for children to exert agency and pursue lines of action that go against dominant institutional frames. We mentioned in the introduction that an important rationale for the public library is to offer access to making for all children and young people. While this library also had an open makerspace for people to pursue their projects, the inventor course was targeted at schools, to provide activities that children do not necessarily have access to in a school setting. However, as we have demonstrated, there is a risk that such activities may become too much like school and that the creative and exploratory characteristics of the maker mindset may become lost. From a social equity perspective, it is crucial that public institutions like the library offer opportunities for imagining through creative exploration, with materials that young people may not have access to at home. How libraries might become places for such activities is still in the making.

Author Contributions: Data curation, G.S.; Formal analysis, G.S.; Supervision, H.C.A. and P.P.; Writing-original draft, G.S.; Writing-review \& editing, H.C.A. and P.P. All authors have read and agreed to the published version of the manuscript.

Funding: This research received no external funding.

Conflicts of Interest: The authors declare no conflict of interest.

\section{References}

1. Jochumsen, H.; Skot-Hansen, D.; Rasmussen, C.H. Towards Culture 3.0-Performative space in the public library. Int. J. Cult. Policy 2017, 23, 512-524. [CrossRef]

2. Willett, R. Making, Makers, and Makerspaces: A Discourse Analysis of Professional Journal Articles and Blog Posts about Makerspaces in Public Libraries. Libr. Q. Inf. Communitypolicy 2016, 86, 313-329. [CrossRef]

3. Barniskis, S.C. Access and Express: Professional Perspectives on Public Library Makerspaces and Intellectual Freedom. Public Libr. Q. 2016, 35, 103-125. [CrossRef]

4. Willett, R. Learning through making in public libraries: Theories, practices, and tensions. Learn. Media Technol. 2018, 43, 250-262. [CrossRef]

5. Filar-Williams, B.; Folkman, M. Librarians as Makers. J. Libr. Adm. 2017, 57, 17-35. [CrossRef]

6. Britton, L. A Fabulous Laboratory: The Makerspace at Fayetteville Free Library. Public Libr. 2012, 51, 30-33.

7. Gee, J.P. Affinity Spaces and 21st. Century Learning. Educ. Technol. 2017, 57, 27.

8. Lave, J.; Wenger, E. Situated Learning: Legitimate Peripheral Participation. Learning in Doing; Cambridge University Press: Cambridge, UK, 1991.

9. Petrich, M.; Wilkinson, K.; Bevan, B. It looks Like Fun, but Are They Learning? In Design, Make, Play: Growing the Next Generation of STEM Innovators; Honey, M., Kanter, D.E., Eds.; Routledge: New York, NY, USA, 2013.

10. Bevan, B.; Gutwill, J.P.; Petrich, M.; Wilkinson, K. Learning Through STEM-Rich Tinkering: Findings from a Jointly Negotiated Research Project Taken Up in Practice. Sci. Educ. 2015, 99, 98-120. [CrossRef]

11. Sheridan, K.; Halverson, E.R.; Litts, B.; Brahms, L.; Jacobs-Priebe, L.; Owens, T. Learning in the Making: A Comparative Case Study of Three Makerspaces. Harv. Educ. Rev. 2014, 84, 505-532. [CrossRef]

12. Cole, M. Cultural Psychology: A Once and Future Discipline; The Belknap Press of Harvard University Press: Cambridge, UK, 1996.

13. Vygotsky, L.S. Imagination and Creativity in Childhood. J. Russ. East Eur. Psychol. 2004, 42, 7-97. [CrossRef]

14. Zittoun, T.; Gillespie, A. Imagination in Human and Cultural Development; Routledge: Abingdon, UK, 2016.

15. Roth, W.-M. Affordances and Constraints of Computers in Science Education. J. Res. Sci. Teach. 1996, $33,995$. [CrossRef]

16. Csikszentmihalyi, M.; Hermanson, K. Intrinsic Motivation in Museums: Why does one want to learn? In Public Institutions for Personal Learning: Establishing a Research Agenda; Falk, J.H., Dierking, L.D., Eds.; American Association of Museums: Washington, DC, USA, 1995; pp. 67-77.

17. Renninger, K.A. Interest and Identity Development in Instruction: An Inductive Model. Educ. Psychol. Motiv. Identity 2009, 44, 105-118. [CrossRef]

18. Valsiner, J. Interest: A metatheoretical perspective. In The Role of Interest in Learning and Development; Lawrence Erlbaum Associates, Inc.: Hillsdale, NJ, USA, 1992; pp. 27-41. 
19. Pierroux, P.; Rudi, J. Teaching Composition with Digital Tools: A Domain-Specific Perspective, in Multidisciplinary Approaches to Art Learning and Creativity. In Fostering Artistic Exploration in Formal and Informal Settings; Knutson, K., Okada, T., Crowley, K., Eds.; Routledge: London, UK, 2020.

20. Hutchins, E. Material anchors for conceptual blends. J. Pragmat. 2005, 37, 1555-1577. [CrossRef]

21. Crowley, K.; Pierroux, P.; Knutson, K. Informal Learning in Museums. In The Cambridge Handbook of the Learning Sciences; Sawyer, R.K., Ed.; Cambridge University Press: Cambridge, UK, 2014; pp. 461-478.

22. Goffman, E. Frame Analysis: An Essay on the Organization of Experience; Harvard University Press: Cambridge, UK, 1974.

23. Krange, I.; Silseth, K.; Pierroux, P. Peers, teachers and guides: A study of three conditions for scaffoling conceptual learning in science centers. Cult. Stud. Sci. Educ. 2019, 15, 1-23. [CrossRef]

24. Silseth, K.; Arnseth, H.C. Frames for learning science: Analyzing learner positioning in a technology-enhanced science project. Learn. Media Technol. 2016, 41, 396-415. [CrossRef]

25. Allan, E.G. Multimodal Rhetorics in the Disciplines: Available Means of Persuasion in an Undergraduate Architecture Studio. Across Discip. 2013, 10, 1-25.

26. Bruner, J.S. The narrative construction of reality. Crit. Inq. 1991, 18, 1-21. [CrossRef]

27. Jornet, A.; Roth, W.-M. Design Thinking, communicating: A Sociogenetic Approach to Reflective Practice in Collaborative Design. In Analysing Design Thinking: Studies of Cross-Cultural Co-Creation; Christensen, B.T., Ball, L.J., Halskov, K., Eds.; CRC Press: Boca Raton, FL, USA; London, UK; New York, NY, USA; Leiden, The Netherlands, 2017; pp. 331-349.

28. Goodwin, C. The Blackness of Black: Color Categories as Situated Practice. In Discourse, Tools and Reasoning: Essays on Situated Cognition; Resnick, L.B., Säljö, R., Pontecorvo, C., Burge, B., Eds.; Springer: Berlin/Heidelberg, Germany; New York, NY, USA, 1997; pp. 111-140.

29. Fangen, K. Deltagende Observasjon, 2nd ed.; Fagbokforl: Bergen, Norway, 2010.

30. Stake, R.E. The Art of Case Study Research; Sage: Thousand Oaks, CA, USA, 1995.

31. Jordan, B.; Henderson, A. Interaction Analysis: Foundations and Practice. J. Learn. Sci. 1995, 4, 39-103. [CrossRef]

32. Lawson, B. How Designers Think: The Design Process Demystified, 4th ed.; Architectural Press: Oxford, UK, 2005. 